\title{
Optimization of Interval Between Overhaul on Steam Power Plant with Risk Based on Human Error and Profit
}

\author{
Emilius Wahyu $^{1}$, Arif Wahjudi ${ }^{2}$
}

\begin{abstract}
Power plant companies have many different standard interval between overhauls. The difference may be due to the different methods used by the company. However, these methods do not take into account aspects of risk, aspects of human error and financial aspects simultaneously. The purpose of this study is to determine the optimal interval overhaul by considering aspects of risk, human error aspects and financial aspects simultaneously. The propsed method to calculate reliability plant model using the Criticality Risk Matrix tool and elimination of equipment that can be overhauled at the time the plant under operating conditions, succeeds in reducing the number of equipment that needs to be analyzed, from 210 to 30 equipment. Parameter reliability plant obtained $\beta$ : 0.9755, $\eta$ : 602.0508, $\gamma:$ 7.5942. The reliability plant model is combined with reliability constant affected by human error resulting in a combined reliability model. The combination of combined unreliability model, multiply to Economical Consequences so that the Total Cost model can be obtained. Genetic algorithm is an effective method to be used in the optimization process of a non linear function. The difference between net income model and total cost will produce profit model, so the optimal overhaul interval can be known by doing optimization on the model so that obtained top1 $=7698$ hours. Optimization of total cost model can be done to find out the latest time the plant must be shutdown to do overhaul in order to avoid cost inefficiency. Optimal time total cost obtained top2 = 17645 hours.
\end{abstract}

Keywords-Interval, Overhaul, Risk, Human Error, Profit.

\section{INTRODUCTION}

A power plant company in West Java, Indonesia as the object of this study, applies overhaul management standards to its power plant installations where overhaul intervals are set for 8000 hours of cumulative operation calculated from the first synchrone on grid to the next overhaul. The interval overhaul is stated for 4-8 months in the manual book and with additional notes if the equipment is in good condition, it can be extended gradually in order to optimize function and lower maintenance costs[1]. Every institution has different steam turbine overhaul intervals[2]. GE's steam turbine service official guide line recommends a 5-year interval, while the Electric Power Research Institute (EPRI) says the overhaul interval time on the turbine is when Nett Present Value calculation method is negative.

\footnotetext{
${ }^{1}$ Emilius Wahyu is with Java-Bali Power Generating Company (PT. PJB), West-Java, Indonesia. E-mail: emilius@ptpjb.com.

${ }^{2}$ Arif Wahjudi is with Department of Mechanical Engineering, Institut Teknologi Sepuluh Nopember (ITS), Surabaya, 60111, Indonesia. E-mail: arybach@me.its.ac.id.
}

Not far from GE, the power generation company in the USA uses a 5-6 year interval for its generating unit and the VGB states the interval between the turbine overhaul is 25.000 hours of operation. The method of determining the inspection interval at a LNG-based processing plant based on risk is formulated[3]. This method assists the process of optimization of inspection intervals (overhaul) by considering the risks associated with production, safety and the environment and combining them with the calculation of system reliability by using previous operating data. The study was developed by adding a correction factor derived from the calculation of probability due to human error so that the calculation of the combination of risk with the reliability of the equipment will change[4]. This human error factor can be calculated using the Success Likehood Index Method (SLIM). The interval between overhauls is obtained by finding the difference between income potential and the level of risk, so that the quality of the overhaul results greatly affects the interval after[5].

\section{METHOD}

The calculation of the optimization of the overhaul interval uses the following equations:

A. Reliability equations with a 3-parameter Weibull distribution[6]

$$
\begin{aligned}
& R \operatorname{comb}(t)=R \operatorname{Rys}(t) \cdot p \\
& \operatorname{Fomb}(t)=1-R \operatorname{Romb}(t) \\
& R(t)=e^{-\left(\frac{t-\gamma}{\eta}\right)^{\beta}}
\end{aligned}
$$

where :

$\mathrm{t} \quad$ : mission time (h)

$\mathrm{T} \quad$ : system life (h)

B : shape parameter atau slope, $>0$

$\eta \quad$ : scale parameter atau characteristic life $>0$

$\gamma \quad$ : location parameter atau failure free life, $-\infty<\gamma<\infty$

Rcomb : combination reliability model

Fcomb : combination unreliability model

B. Equation Human Error Probability (HEP)[7]

$$
\begin{aligned}
& \mathrm{SLI}_{\mathrm{k}}=\sum R_{j k} x W_{j} \\
& \mathrm{LOG}(\mathrm{HEP})=\mathrm{a} \times \mathrm{SLI}+\mathrm{b} \\
& \mathrm{P}=\prod_{k=1}^{m}\left(1-H E P_{k}\right)
\end{aligned}
$$

where :

$\mathrm{P} \quad$ : human error reliability

Rjk : scale rating task $\mathrm{k}$ on PSF i

$\mathrm{Wj} \quad$ : weight of normalization 
SLI : Succes Likelyhood Index task k

HEP : human error probability

\section{Total Cost Equation}

$$
\begin{aligned}
& E C T=\max (E C A L+E C H H L)_{i}+\sum_{i=1}^{n} E C S I M+ \\
& E C P L \\
& R I S K e=F_{s y s}(t) \times E C T \\
& K c=K r+R I S K e
\end{aligned}
$$

where :

ECT : Economic Consequences of Failure (Rp)

Fsys : combination probability of failure

RISKe : Risk (Rp)

ECAL : Economic Consequences of Asset Lost (Rp)

ECHHL : Economic Consequences of Human Health Loss (Rp)

ECSIM : Economic Consequences of Shutdown Inspection and Maintenance Cost (Rp)

ECPL : Economic Consequenes of Production Loss (Rp)

$\mathrm{Kr} \quad$ : Total Maintenance Cost (Rp)

Kc : Total Cost (Rp)

D. Profit Equation[5]

where :

$$
\begin{aligned}
& \mathrm{Z}=\mathrm{Zbrutto}-\mathrm{Qb} \times \mathrm{CP} \\
& \mathrm{V} \text { = Z”-Kc” }
\end{aligned}
$$

$\mathrm{Z} \quad$ : net income (Rp)

Zbrutto : income brutto (Rp)

$\mathrm{Qb} \quad$ : coal consumption (t/h)

$\mathrm{CP} \quad$ : the price of coal $(\mathrm{Rp} / \mathrm{kg})$

Z” $\quad$ : Z per unit time $(\mathrm{Rp} / \mathrm{h})$

Kc” : Kc per unit time $(\mathrm{Rp} / \mathrm{h})$

V” : profit per unit time $(\mathrm{Rp} / \mathrm{h})$

\section{RESULT AND DISCUSSION}

Modeling is implemented in 5 modules :
1. selection of equipment

2. calculation of plant, human error and combined reliability model

3. calculation of risk model

4. calculation of profit model

5. optimization of profit function and total cost

Selection of equipment is done with the aim of simplifying the process of analysis by reducing equipment with certain categories in the next analysis process. Reliabilty Block Diagram (RBD) system and plant level is structured to facilitate the analysis of modeling. Equipment selection requires input data downtime equipment to be able to calculate probability failure. Probability failure is used to determine the probability value. Calculating the impact value if a down equipment can be done using RBD instructions. Determination of risk categories, based on Criticality Risk Matrix in the figure 1 can be implemented so that it can be done eleminasi on equipment that has low risk category. The process of elemination at this stage succeeded in reducing 210 to 51 equipment.

The next process is to calculate the Mean Time Between Failure (MTBF) of the redundant equipment that passed the previous elemination. An equipment can be eliminated to be removed from subsequent analysis if the MTBF minus equipment system is greater than the duration of the overhaul equipment. Eliminated equipment will be overhauled when the plant in operating condition. The advanced elemination process successfully reduces 51 to 30. RBD is revised by eliminating eliminated equipment.

The compilation of plant reliability model is done by fitting data down time using final revision RBD and Blocksim software tool, yielding parameter $\beta$ : 0.9755, $\eta$ : $602,0508, \gamma: 7,5942$ on the equation

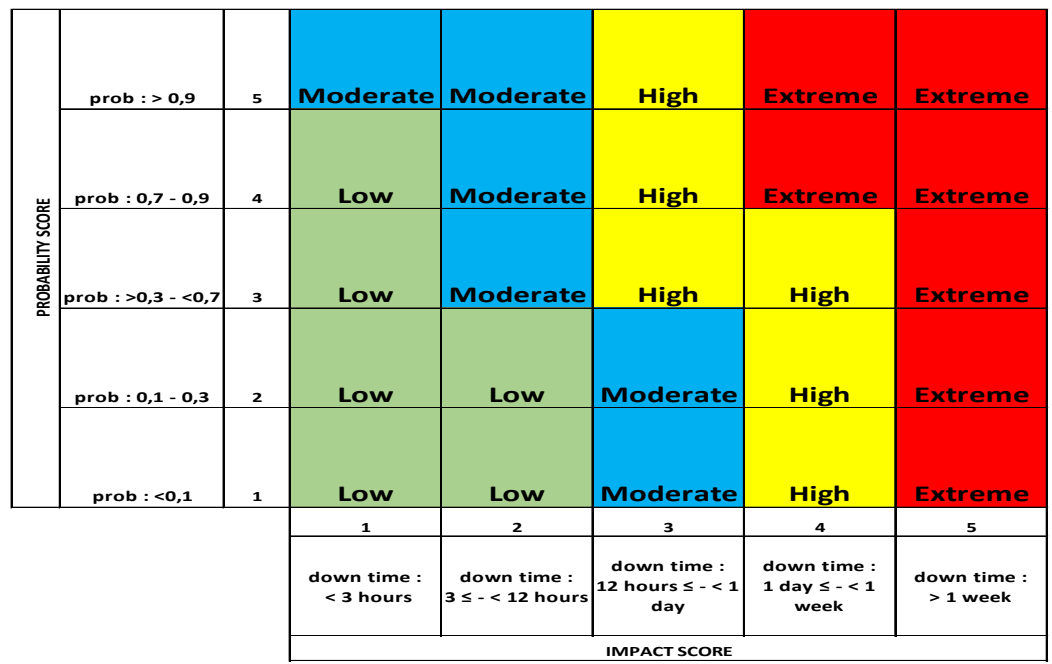

Figure 1. Criticality Risk Matrix

The calculation of human reliability model is done using SLIM tool. There are 6 Performace Shaping Factors (PSF) that have the potential to affect the quality of overhaul results, namely:

1. Completeness of the tool
2. Adequacy of work procedures

3. Adequacy of personnel knowledge to setting standards

4. Condition of exhausted body

5. Work experience

6. Satisfaction with work wages 
PSF will affect the value of human error probability (HEP) on 22 overhaul activity. The result of SLIM analysis shows that the pump / fan realignment work has the highest HEP that is 0.0001595 and the total reliability value is 0.9969. Using the equation (3) can be compiled combination unreliability model as follows:

$$
F \operatorname{comb}(t)=1-\left(0,9969 \cdot e^{-\left(\frac{t-7,5942}{602,0508}\right)^{0,9755}}\right)
$$

Risk is the multiplication of probability with impact. Probability can use the combination unreliability model (Fcomb), while the impact is derived from the calculation of Total Economical Consequences of Failure (ECT). ECT consists of 4 components, namely: ECAL, ECHHL, ECSIM and ECPL. Calculation of the component by using formula (7) obtain ECT model as follows:

$$
\begin{aligned}
\operatorname{ECT}(t)= & \left(1-\frac{1}{0,9827} e^{-\left(0,2475+\frac{t}{213120}\right)^{2,9}}\right) \times 331470577932+ \\
& \left(1-\frac{1}{0,9827} e^{-\left(0,2475+\frac{t}{213120}\right)^{2,9}}\right) \times 1981800000+ \\
& 10099934727+5 \times 10^{10}+468547 t+310,26 t^{2}
\end{aligned}
$$

From the above ECT model can be punctured risk model per unit time (RISKe "), as follows:

$$
\begin{aligned}
\text { RISKe }^{\prime \prime}(t)= & \frac{1}{\mathrm{t}}\left(1-0,9969 \cdot e^{-\left(\frac{t-7,5942}{602,0508}\right)^{0,9755}}\right) \times \\
& \left(-339322659949,12 e^{-\left(0,2475+\frac{t}{213120}\right)^{2,9}}+\right. \\
& \left.310,26 t^{2}+42854 t+399422594676\right)
\end{aligned}
$$

Total Maintenance Cost Model (Kr) is prepared using actual maintenance data from research object, and obtained model as follows:

$$
K r^{\prime \prime}=\frac{1}{t}(32.653 .877 .360+1.102 .449 t)
$$

Total Cost (Kc ") model can be obtained by summing RISKe" and $\mathrm{Kr} "$

Net income can be obtained from the gross income difference with the fuel cost. Fuel costs will change according to NPHR changes, so it is necessary to model NPHR. Based on NPHR data analysis with linear regression can be obtained the model as follows:

$$
\operatorname{NPHR}(t)=0,0321 t+2625,2
$$

Calculation of formula no (10) with data HHV $=4813$ $\mathrm{kCal} / \mathrm{kg}$ with the average price of Rp. 792.632, - per ton. Data of March 2018 for CF is 0.88 and HPP $611.3 \mathrm{Rp} /$ $\mathrm{kWh}$ can be obtained net income model ( $\mathrm{Z}$ ") as follows:

$$
Z^{\prime \prime}(t)=45672445,16-1347,47 t
$$

After Kc "and Z" are known, then we can arrange profit model ( $\mathrm{V}$ ") using equation no (11), with result as follows:

$$
\begin{aligned}
V^{\prime \prime}(t)= & (45672445,16-1347,47 t)- \\
& \frac{1}{t}\left(1-0,9969 \cdot e^{-\left(\frac{t-7,5942}{602,0508}\right)^{0.9755}}\right) \times
\end{aligned}
$$

$$
\begin{aligned}
& \left(-339322659949,12 e^{-\left(0,247+\frac{t}{213120}\right)^{2,9}}+310,26 t^{2}+\right. \\
& 468547+399422594676)-\frac{1}{t}(3265387760+ \\
& 1102449 t)
\end{aligned}
$$

Maximization optimization of profit function is done to get the time point $\left(\mathrm{t}_{\mathrm{op} 1}\right)$ on the highest profit per hour. Optimization of minimization of total cost function is done to get the time point $\left(\mathrm{t}_{\mathrm{op} 2}\right)$ at the lowest total cost value. Non linear optimization is done using Genetic Algorithm method, with top.

In the graph $\mathrm{V}$ "can be obtained the point of intersection with the $\mathrm{x}$ axis. The A point is the time at which the plant starts to get an hourly profit and point B where the plant begins to lose. From the calculation obtained point $\mathrm{A}=$ 2.449 hours and point $\mathrm{B}=23,824$ hours. Point $\mathrm{t}_{\mathrm{op} 1}$ positioning of the graph can be seen in the figure 2 .

result $=7.698$ hours for maximum profit, and $\mathrm{t}_{\mathrm{op} 2}: 17.645$ hours for lowest total cost.

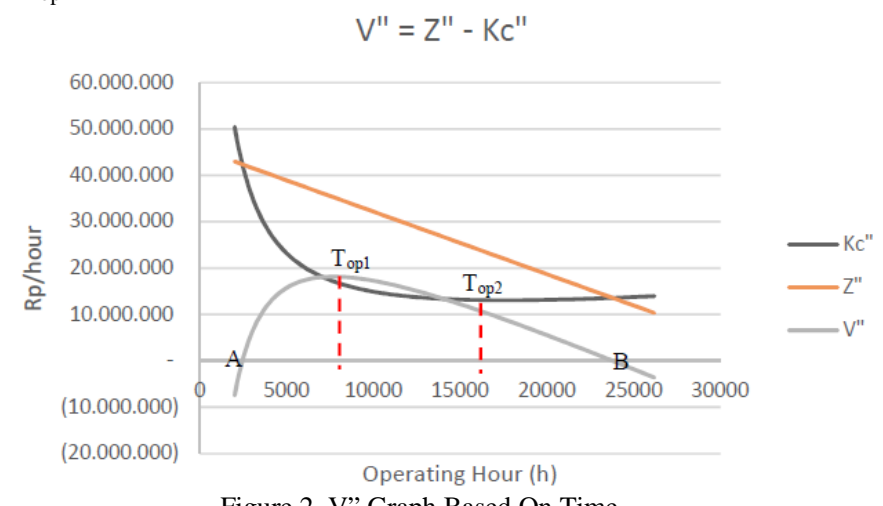

Figure 2. V” Graph Based On Time.

\section{REFERENCES}

[1] SCP JO, Turbine Maintenance Manual Beijing Beizhong Revised Edition 2. SCP JO, 2010.

[2] J. Latcovich and International Association of Engineering Insurers, "Maintenance and Overhaul of Steam Turbines HMN Series Steam Turbine-Courtesy Siemens Power Corporation Working Group," Moscow, 2005.

[3] A. Hameed and F. Khan, "A framework to estimate the risk-based shutdown interval for a processing plant,” J. Loss Prev. Process Ind., vol. 32, pp. 18-29, Nov. 2014.

[4] A. Hameed, F. Khan, and S. Ahmed, "A risk-based shutdown inspection and maintenance interval estimation considering human error,” Process Saf. Environ. Prot., vol. 100, pp. 9-21, Mar. 2016.

[5] A. Rusin and A. Wojaczek, "Optimization of power machines maintenance taking the risk into consideration," Eksploat. $i$ Niezawodn. - Maint. Reliab., vol. 14, no. 1, pp. 72-76, 2012.

[6] ReliaSoft Corporation, Life Data Analysis Reference. ReliaSoft Corporation, 2015.

[7] M. Hakam and R. A. Ratriwardhani, "Identifikasi bahaya pada pekerjaan grinding di sebuah perusahaan manufaktur dengan menggunakan pendekatan succes likelihood index methode Indonesia,” in Seminar Nasional Manajemen Teknologi XIX, 2013. 